\title{
OCORRÊNCIA DE EVENTOS SEVEROS EM REGIÕES AGRÍCOLAS DO RIO GRANDE DO SUL
}

\author{
Dejanira Ferreira BRAZ ${ }^{1}$, Luciana Barros PINTO' ${ }^{1}$, Claudia Rejane Jacondino de CAMPOS $^{1}$
}

(1) Programa de Pós Graduação em Meteorologia, Universidade Federal de Pelotas -UFPel, Av. Engenheiro Ildefonso Simões Lopes, 2751 - Arco-íris, CEP 96060-290.Pelotas, RS. Endereços eletrônicos: deja_braz@yahoo.com.br, luciana.pinto@ufpel.edu.com, cjcampos@ufpel.edu.br

\author{
Introdução \\ Materiais e métodos \\ Resultados \\ Conclusão \\ Agradecimento \\ Referências
}

\begin{abstract}
RESUMO - Eventos severos (ES) podem causar prejuízos econômicos e sociais, um exemplo são os danos causados às plantações do Estado do Rio Grande do Sul (RS). Neste trabalho buscou-se analisar a ocorrência dos ES que atingiram a agricultura no RS, no período de 2003 a 2012, caracterizando espacial e temporalmente o ES mais frequente, bem como sua distribuição e a relação deste com o fenômeno ENOS. Para isto, foram utilizados registros de ES ocorridos na área rural por municípios do RS, obtidos no banco de dados da Defesa Civil do RS (DCRS). Observou-se que houve registro de ES, com maior frequência no período de verão e outono, sendo que os ES mais frequentes foram estiagem, granizo e vendaval, respectivamente. A estiagem, em geral ocorre com maior frequência nos meses de dezembro a julho, e em períodos sem a atuação do fenômeno El Niño Oscilação Sul (ENOS). Mas ao compararmos a ocorrência deste evento dentro das fases do ENOS, constatou-se que os casos mais frequentes são em períodos de La Niña e El Niño Modoki. A região que tem maior frequência na ocorrência desse ES é a metade norte do Estado, como foi verificado através das imagens NDVI.
\end{abstract}

Palavras-chave: Estiagem, ENOS, NDVI.

\begin{abstract}
Severe events (ES) can cause economic and social damage, an example is the damage caused to the State plantations of Rio Grande do Sul (RS). This study aimed to analyze the occurrence of ES which hit agriculture in RS in the period 2003 to 2012 , featuring spatially and temporally the most frequent ES as well as its distribution and its relationship with the ENSO phenomenon. For this, ES records were used occurred in rural areas by municipalities in the RS, obtained in civil defense database RS (DCRS). It was observed that there was ES record, most often during the summer and autumn, and the most frequent ES were drought, hail and gale, respectively. The drought usually occurs more frequently in the months from December to July, and at times without the actions of the El Niño Southern Oscillation (ENSO). But when comparing the occurrence of this event within the phases of ENSO, it was found that the most frequent cases are in periods of La Niña and El Niño Modoki. The region has more frequent occurrence of this ES is the northern half of the state, as verified through the NDVI images.
\end{abstract}

Keywords: Drought, ENSO,NDVI

\section{INTRODUÇÃO}

Com o aumento da população mundial uma das maiores preocupações vêm sendo a demanda por alimentos. A produção de alimentos, por sua vez, cresce com a tecnologia e com a expansão de áreas agrícolas. Mas, ainda assim, um dos fatores limitantes é o clima, que pode beneficiar ou impedir a produção não só por suas características constantes (Rocca et al.; Berlato; Fontana, 1997; Costa, 2006; Pellegrino et al., 2007; Cavalcanti et al., 2009; Barteko et al., 2010; Santos et al., 2011), como quantidade de radiação, mas também por seus fenômenos meteorológicos que variam de uma safra para outra, como o granizo ou a estiagem (Reis et al.,2012; De Moura et al.,2013).

O Estado do Rio Grande do Sul (RS) é o terceiro maior produtor e exportador de grãos do Brasil, sendo responsável por aproximadamente $15,5 \%$ da safra total do país (IBGE, 2014). Um dos principais fatores que influencia no desenvolvimento das safras agrícolas é o clima do RS, classificado segundo a Normal Climatológica apresenta temperatura máxima superior a $23,9^{\circ} \mathrm{C}$ e mínima inferior a $13,5^{\circ} \mathrm{C}$, precipitação com máxima de $1.823 \mathrm{~mm}$ e mínimo de $1.228,9 \mathrm{~mm}$ (INMET, 2015).

A variabilidade interanual da precipitação em toda a região Sul do país está diretamente ligado a fenômenos de circulação atmosférica, tanto em escala regional quanto global. Os principais sistemas meteorológicos que atuam no RS são os sistemas convectivos de mesoescala (SCM) (Sanjarabdoulaev \& Gomes, 1998; Campo \& Silva, 2010; Campos \& Eichholz, 2011) responsáveis por grade parte da precipitação nas estações quentes (OND: Outubro-NovembroDezembro e JFM: Janeiro-Fevereiro-Março) e os sistemas frontais (SF), nas estações frias 
(AMJ: Abril-Maio-Junho e JAS: Julho-AgostoSetembro). Em grande escala, pode-se citar o fenômeno climático ENOS (El Niño Oscilação Sul), onde episódios quentes (anomalia positiva de TSM, El Niño - EN), influenciam na região sul do Brasil com anomalias positivas de precipitação pluvial, e os episódios frios (anomalias negativas de TSM, La Niña - LN), estão relacionados à diminuição da precipitação pluvial na região (Cera \& Ferraz, 2015). A diversidade de fenômenos que atuam na variação da precipitação do RS, também influencia na intensidade, na distribuição e frequência da ocorrência de eventos intensos, também denominados Eventos Severos (ES). Os $\mathrm{ES}$, tais como, vendaval, granizo, enchente, estiagem, entre outros, causam grandes impactos econômicos e sociais nas regiões onde atuam.

A maioria dos problemas que afetam as safras brasileiras deve-se à ocorrência de secas, chuvas fortes e geada (Da Silva, 1996; Aguiar, 2005; Lazzari \& Fee, 2006; Araújo et al., 2012). Um tipo de ES bastante comum no RS, principalmente no período de primavera-verão, é a estiagem, frequentemente relacionadas com o fenômeno ENOS, principalmente na sua fase fria (LN) (Bergamaschi, 2004; Goerl et al., 2009; Jacóbsen, 2004; Nedel et al., 2012). De acordo com levantamentos da EMATER/RS, em anos de LN podem ocorrer perdas de até 5,6 milhões de toneladas de grãos (EMATER, 2014). Por isso, o fenômeno LN e sua associação com secas são de interesse dos agricultores no sul do Brasil. A ocorrência de ES, ao longo do ciclo de desenvolvimento das culturas agrícolas pode acarretar perdas de rendimento de grãos, e, consequentemente, redução das estimativas de safra. As reduções de safra (quebras de safra) têm impactos sobre políticas de definição de preços, de logística de transportes e de planejamento de estoques públicos, ou seja, afetam diretamente a seguridade alimentar de um país ou região (Assad et al., 2007).

Neste contexto, a análise, a caracterização e o mapeamento de eventos como a estiagem tornam-se importantes no sentido de conhecer a distribuição espacial e temporal desses eventos dentro de uma região. As imagens de satélite representam importante fonte de informação para este propósito. Entre as alternativas disponíveis, o sensor de baixa resolução Terra/MODIS tem sido largamente empregado para o desenvolvimento de métodos voltados ao mapeamento de áreas extensas (Jacóbsen, 2004; Ribeiro et al., 2007; Sartori et al., 2009). Dentre os produtos MODIS, destaca-se o Índice de Vegetação por Diferença Normalizada (NDVI Normalized Difference Vegetation Index), que possibilita o monitoramento da vegetação por indicar uma associação direta entre o índice de área foliar e as condições da biomassa ( Turner et al., 1999; Ribeiro et al., 2007)

Neste sentido, a identificação dos tipos de ES que mais atingem a agricultura dentro de uma determinada região, assim como a distribuição temporal e espacial dessas ocorrências torna-se uma ferramenta de apoio ao planejamento agrícola, a fim de se diminuir perdas em decorrência de fenômenos meteorológicos/climáticos. Sendo assim, o objetivo deste trabalho foi analisar a ocorrência dos ES que atingiram a agricultura no RS entre 2003 a 2012, e caracterizar espacial e temporalmente o ES mais frequente, bem como sua relação com o fenômeno ENOS. E, avaliar a influência das variações de precipitação registrada no RS durantes os eventos mais intensos e o impacto destas variações no vigor da vegetação.

\section{MATERIAL E MÉTODOS}

Para a avaliação dos ES que causam danos à agricultura no Estado do Rio Grande do Sul (ESRSr), foram utilizados dados de registro diário de ES por municípios atingidos, durante o período de 01 de janeiro de 2003 a 31 de dezembro de 2012, obtidos no banco de dados da Defesa Civil do RS (DCRS, 2014). A DCRS dividi o Estado em onze coordenadorias Regionais de Defesa Civil (REDECs) (Figura 1). Para este estudo, foram considerados apenas os eventos do tipo: granizo, granizo/vendaval, vendaval, enxurrada, enchente, alagamento e estiagem, que atingiram somente as zonas rurais do Estado. 


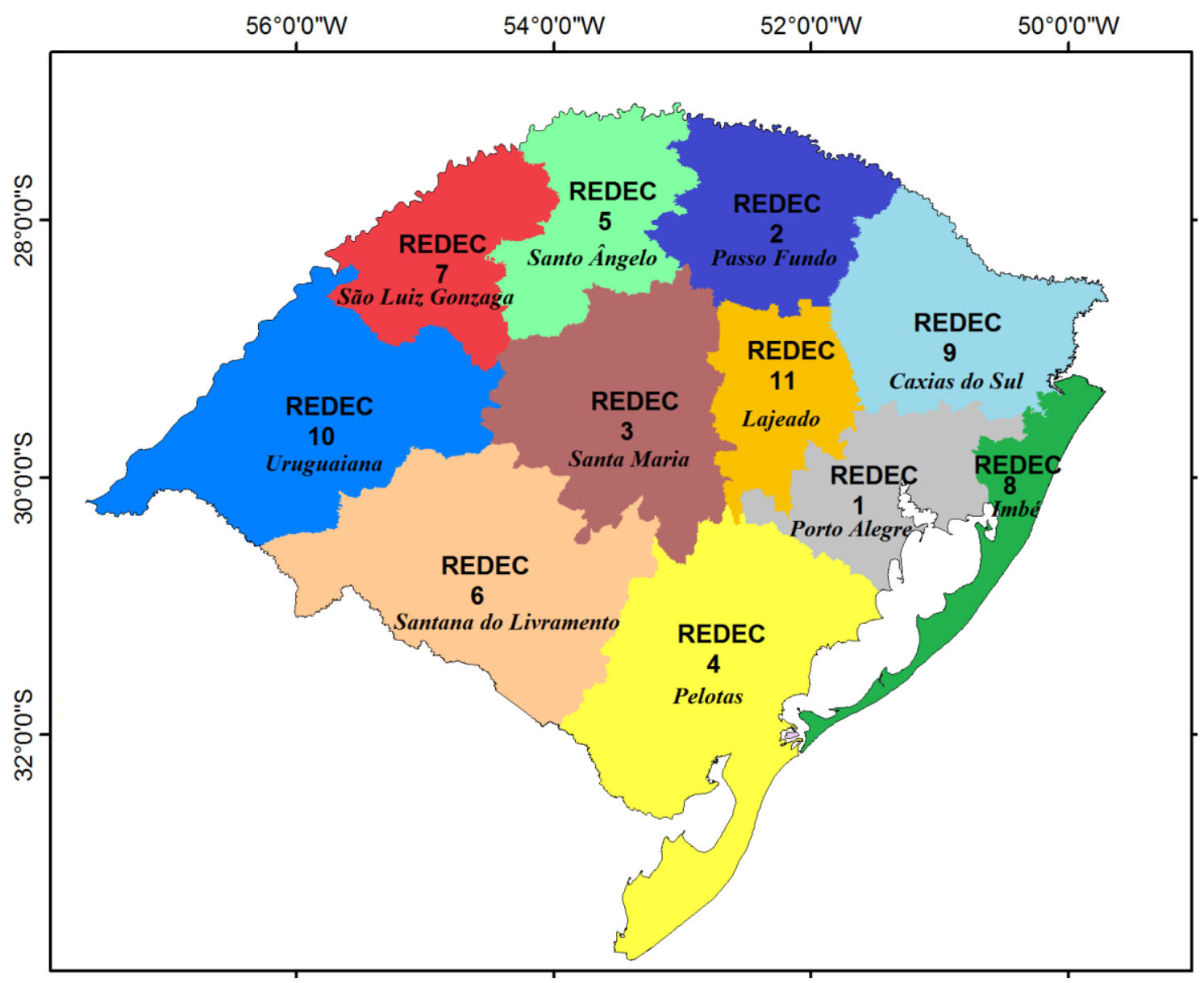

Figura 1. Coordenarias Regionais da Defesa Civil (REDECs).

Selecionou-se os dias com registro de ES, onde, primeiramente, computou-se o total de dias em cada mês com ocorrência de cada um dos tipos de ES observados e, posteriormente, o total em dias em cada ano para todo o período de estudo. Em seguida, foi feito a identificação do período com maior e menor número de registros de ES.

Após a identificação do ES mais frequente que atingiu a área rural do RS (ESf), computouse o número total de registros deste evento em cada ano e mês do período de estudo a fim de avaliar sua a distribuição anual e sazonal. Para se identificar o padrão de ocorrência do ESf em relação à atuação de fenômenos ENOS foram utilizados os dados de classificação de eventos ENOS, conforme os critérios adotados pelo National Weather Service Climate Prediction Center (NCEP/NOAA, 2014), em que El Niño (quente), La Niña (frio) e Neutros, em função da variação da anomalia da temperatura da superfície do mar (TSM) na região do Niño 3.4 do Oceano Pacífico Equatorial. Contabilizou-se o total anual e mensal dos registros do ESf sob a atuação do fenômeno ENOS no período de estudo.

Em relação ao número de municípios atingidos em cada REDEC contabilizou-se o total de municípios atingidos pelo ESf em cada mês dentro do período de 2003-2012 por REDEC, ou seja, se em anos diferentes houve o registro de estiagem no mesmo mês (ex. janeiro) num município, ou mais de um registro para o mesmo município dentro de um mês, esse município foi contabilizado apenas uma vez. Analisou-se a distribuição geográfica da ocorrência total de estiagem por ano em cada REDEC, para a identificação da região do Estado mais afetada, utilizando o mapa da divisão de REDECS estipulada pela Defesa Civil. Neste caso todas as ocorrências foram contabilizadas, ou seja, se foram registradas mais de uma ocorrência por mês dentro do mesmo município, todas foram consideradas. Como os dados utilizados neste estudo foram os registros de ES feitos junto à defesa civil, não foi possível analisar a duração ou intensidade de 
cada evento, e sim apenas se houve registro ou não.

Para analisar a distribuição espacial da precipitação pluvial no RS durante as estações dos anos de maior número de registros do ESf, foram utilizados dados de precipitação mensal acumulada $(\mathrm{mm})$ para o período de 2003 até 2012, obtidos junto ao Banco de Dados Meteorológicos para Ensino e Pesquisa (BDMEP/INMET), de 17 estações meteorológicas de superfície distribuídas no RS, pertencentes ao $8^{\circ}$ DISME/INMET ( $8^{\circ}$ Distrito de Meteorologia do Instituto Nacional de Meteorologia). Assim, foram calculados os totais trimestrais para cada estação do ano, divididos em DJF - verão, MAM - outono, JJA inverno e SON - primavera, e as anomalias de precipitação, através da diferença entre a precipitação acumulada $(\mathrm{mm})$ trimestral (DJFMAM-JJA-SON) e a trimestral da Normal
Climatológica de 1961-1990 do

INMET (Instituto Nacional de Meteorologia).

Para realização da análise da Normalized Difference Vegetation Index (NDVI) foram utilizadas as bandas 4 e 3 do satélite LANDSAT5 TM, ou seja, a banda da região do infravermelho próximo e do vermelho, respectivamente, para os anos de 2005 e 2012, disponibilizadas pelo Instituo Nacional de Pesquisas Espaciais (INPE), importadas e georreferenciadas utilizando-se o Sistema de Informação Geográfica SIG IDRISI-Andes. O cálculo da relação de bandas e geração dos NDVI foi executado pela função Imagem Processing >Transformation> VEGINDEX. Utilizando o VEGINDEX, que oferece 19 tipos de cálculos de índice de vegetação, foram elaborados os mapas de NDVI de ambos os anos considerados e variando de $-1 \mathrm{a}+1$ em tons de cinza.

\section{RESULTADOS E DISCUSSÃO}

Pela análise do número de dias com ocorrência de ES foi possível verificar que um total de 852 dias (Tabela 1) com registros de ES, que representam aproximadamente $23 \%$ dos 3.653 dias (10 anos) do período de estudo. No qual, os tipos de ES mais frequentes foram: estiagem (432 dias, 50,7\%), seguido de granizo (120 dias, 14,08\%), vendaval (117 dias, $13,73 \%$ ), enxurrada (88 dias, $10,32 \%$ ), enchente
(62 dias, 7,27\%), granizo/vendaval (27 dias, $3,16 \%$ ) e alagamento (6 dias, $0,7 \%$ ). Os resultados concordam com o que já foi observado por outros autores, no qual os ES que são mais frequentes no RS são estiagem, granizo e vendava (Nedel et al., 2012; Rasera \& De Campos, 2013; De Vargas Jr \& De Campos, 2015).

Tabela 1. Número de dias/mês com a atuação de ES de 2003-2012.

\begin{tabular}{|c|c|c|c|c|c|c|c|c|c|c|c|c|c|c|}
\hline Eventos & $\mathrm{J}$ & $\mathrm{F}$ & M & A & M & $\mathrm{J}$ & $\mathrm{J}$ & A & $\mathrm{S}$ & $\mathrm{O}$ & $\mathrm{N}$ & $\mathrm{D}$ & Total & $\begin{array}{l}\text { Contribuição } \\
\%\end{array}$ \\
\hline Estiagem & 79 & 58 & 96 & 67 & 47 & 20 & 9 & 4 & 2 & 1 & 0 & 49 & 432 & 50,7 \\
\hline Granizo & 10 & 6 & 4 & 7 & 6 & 4 & 10 & 5 & 22 & 20 & 14 & 12 & 120 & 14,08 \\
\hline Vendaval & 12 & 3 & 9 & 2 & 2 & 4 & 4 & 7 & 16 & 16 & 25 & 17 & 117 & 13,73 \\
\hline Enxurrada & 20 & 6 & 8 & 1 & 6 & 0 & 1 & 2 & 4 & 5 & 14 & 21 & 88 & 10,32 \\
\hline Enchente & 6 & 3 & 2 & 0 & 1 & 2 & 5 & 3 & 10 & 5 & 14 & 11 & 62 & 7,27 \\
\hline Granizo/vendaval & 8 & 1 & 0 & 1 & 1 & 2 & 1 & 2 & 3 & 4 & 2 & 2 & 27 & 3,16 \\
\hline Alagamento & 0 & 0 & 0 & 0 & 0 & 1 & 2 & 0 & 1 & 0 & 0 & 2 & 6 & 0,7 \\
\hline Total & 135 & 77 & 119 & 78 & 63 & 33 & 32 & 23 & 58 & 51 & 69 & 114 & 852 & 100 \\
\hline
\end{tabular}

Pôde-se verificar, a partir da análise sazonal do número de dias com registros de $\mathrm{ES}$, que estes eventos ocorreram em todos os meses (Tabela 1), porém, o primeiro período, de dezembro até maio (meses de verão e outono) foi o que apresentou a maior frequência de número de dias com registros de ES (68,78\% - 586 dias) e, o segundo período, que vai de junho até novembro 
(meses de inverno e primavera), apresentou menor frequência de ES (31,22\% - 266 dias). O verão foi a estação que apresentou maior número de ocorrência de ES (Tabela 1) que atingiram as regiões rurais do $\mathrm{RS}$, coincidindo com o padrão definido para a ocorrência de ES de maneira geral (áreas urbanas e rurais) no Estado do RS (Rasera \& Campos, 2013). Os meses com maior frequência foram dezembro, janeiro e março que juntos somaram 43,19\% (368 dias) (Tabela 1) devido ao fato de que nos períodos quentes, a maior disponibilidade energética devido à maior incidência de radiação proveniente do Sol favorece processos convectivos na atmosfera e, consequentemente, o desenvolvimento de SCM, os quais estão diretamente relacionados à ocorrência de ES (Salio et al., 2007) como granizos e vendavais (Reis et al., 2011; Nedel et al., 2012), os ES de estiagem, geralmente são influenciados pelos fenômenos LN que provocam um déficit negativo de precipitação no RS (Cunha, 1997; Grimm et al., 2000; Jacóbsen, 2004).
A estiagem foi o ES mais frequente durante o período de estudo, sendo assim, analisou-se o número de dias por mês com a atuação deste fenômeno, independente do número de municípios atingidos. Os meses com maior frequência de estiagem foram de dezembro a junho, que apresentam 416 dias com ocorrência do evento, correspondendo a $96,3 \%$, sendo o mês de maio o que mais apresentou casos de estiagem, num total de 96 dias (Tabela 2). Esse resultado é importante uma vez que as principais culturas agrícolas do RS são cultivadas no verão (milho, soja e arroz) período em que a ocorrência de estiagens refletem em grandes danos à economia do Estado(Lazzari, 2005). Em comparação a isso, os meses com menor frequência foram de julho a novembro (16 registros $-3,7 \%$ do total), sendo que o mês com menor número de dias de estiagem foi o mês de novembro, que não apresentou registro do evento (Tabela 2). Pode-se então constatar que as estações de verão e outono mostram uma maior incidência de eventos de estiagem.

Tabela 2. Número de dias/mês com a atuação de estiagem. Para identificar a influência dos fenômenos ENOS os meses com atuação dos fenômenos EL Niño (fonte em itálico), La Niña (fonte em negrito) e Neutro (fonte normal). Para o período de 01/01/2003 até 31/12/2012 no estado do Rio Grande do Sul.

\begin{tabular}{|c|c|c|c|c|c|c|c|c|c|c|c|c|c|c|c|c|}
\hline Anos & $\mathrm{J}$ & $\mathrm{F}$ & $\mathrm{M}$ & $\mathrm{A}$ & M & $\mathrm{J}$ & $\mathrm{J}$ & A & $\mathrm{S}$ & $\mathrm{O}$ & $\mathrm{N}$ & $\mathrm{D}$ & Total & El Niño & La Niña & Neutro \\
\hline 2003 & 2 & 1 & 1 & 0 & 0 & 0 & 0 & 0 & 0 & 1 & 0 & 0 & 5 & 3 & 0 & 2 \\
\hline 2004 & 1 & 9 & 24 & 17 & 3 & 0 & 0 & 1 & 1 & 0 & 0 & 5 & 61 & 7 & 0 & 54 \\
\hline 2005 & 25 & 19 & 13 & 1 & 0 & 0 & 0 & 0 & 1 & 0 & $\mathbf{0}$ & 4 & 63 & 25 & 4 & 34 \\
\hline 2006 & 3 & 4 & 17 & 7 & 7 & 2 & 2 & 0 & 0 & 0 & 0 & 0 & 42 & 0 & 24 & 18 \\
\hline 2007 & 0 & 0 & 4 & 3 & 0 & 0 & 0 & 0 & $\mathbf{0}$ & $\mathbf{0}$ & $\mathbf{0}$ & 0 & 7 & 0 & 0 & 7 \\
\hline 2008 & $\mathbf{0}$ & 0 & 21 & 12 & 1 & 1 & 0 & 0 & 0 & 0 & $\mathbf{0}$ & 16 & 51 & 0 & 51 & 0 \\
\hline 2009 & 17 & 4 & 10 & 21 & 19 & 2 & 0 & 0 & 0 & 0 & 0 & 0 & 73 & 0 & 31 & 42 \\
\hline 2010 & 0 & 0 & 0 & 0 & 0 & 0 & $\mathbf{0}$ & 0 & $\mathbf{0}$ & $\mathbf{0}$ & $\mathbf{0}$ & 2 & 2 & 0 & 2 & 0 \\
\hline 2011 & 6 & 7 & 0 & $\mathbf{0}$ & 0 & 0 & 2 & 1 & $\mathbf{0}$ & $\mathbf{0}$ & $\mathbf{0}$ & 17 & 33 & 0 & 30 & 3 \\
\hline 2012 & 25 & 14 & 6 & 6 & 17 & 15 & 5 & 2 & 0 & 0 & 0 & 5 & 95 & 0 & 45 & 50 \\
\hline Total & 79 & 58 & 96 & 67 & 47 & 20 & 9 & 4 & 2 & 1 & 0 & 49 & 432 & 35 & 187 & 210 \\
\hline El Niño* & 27 & 1 & 0 & 0 & 0 & 0 & 0 & 1 & 1 & 0 & 0 & 5 & 35 & & & \\
\hline La Niña** & 51 & 29 & 54 & 12 & 1 & 1 & 0 & 0 & 0 & 0 & 0 & 39 & 187 & & & \\
\hline Neutro & 1 & 28 & 42 & 55 & 46 & 19 & 9 & 3 & 1 & 1 & 0 & 5 & 210 & & & \\
\hline
\end{tabular}


Verificou-se que os anos com maior frequência de estiagens foram os de 2009 e 2012, que juntos somam 168 dias de ocorrência, correspondendo a 38,9\% do total (Tabela 2). Os anos que tiveram menor número de dias com ocorrências de estiagem foram 2003, 2007 e 2010, o que representou 14 dias com registros estiagem, ou seja, apenas 3,24\% das ocorrências de estiagem foram nesses anos (Tabela 2).

Observou-se que embora atuação de La Niña seja caracterizada por diminuição na precipitação no RS, que geralmente levam a casos de estiagem, o maior número de dias com registros de estiagem ocorreu em anos Neutros (48,6\% dos registros ou seja, 210 dias), seguidos por $43,28 \%$ durante a atuação do fenômeno La Niña (187 dias), e 8,10\% em anos de El Niño (35 dias). Dentro do período de La Niña os anos de 2008, 2009, 2011 e 2012 foram os que apresentaram maior ocorrência de estiagem, totalizando $83,95 \%$ (157 dias) do total de dias dentro deste tipo de fenômeno. Os anos que resultaram maiores em períodos de estiagem foram: em 2005 EL Niño (25 dias - 67,56\%), e em períodos neutros, 2004, 2009 e 2012 (144 dias - 69,23\%). Estudos mais recentes relacionados ao clima mostram características diferentes da atuação do El Niño, o chamado El Niño Modoki .Esse fenômeno se caracteriza por apresentar anomalias positivas de Temperatura da Superfície do Mar (TSM) na região central do Oceano Pacífico (e não no leste do Oceano Pacífico próximo à costa peruana como é observado no El Niño tradicional) e provoca efeitos contrários daqueles do El Niño no regime de precipitação, ou seja, causa estiagem nas regiões sul e sudeste e chuvas acima da média climatológica no nordeste do Brasil (Tedeschi \& Cavalcanti, 2004; Junior \& Pezzi, 2011). Visto que foi comprovado no ano de 2004 com atuação do El Niño Modoki provocando a deficiência na precipitação, causando a estiagem nos meses de agosto, setembro e dezembro. Essa atuação do El Niño Modoki refletiu no começo do ano seguinte e dessa forma justifica a ocorrência do mês de janeiro de 2005 ter tido um elevado número de dias com estiagem, mesmo estando sobe a atuação do EN. A atuação da estiagem nesses anos foi constata com grandes quebras de safras e prejuízos para os agricultores do RS(Lazzari,
2005; Lazzari \& Fee, 2006; Amado et al., 2007; Pellegrino et al., 2007; Streck et al., 2009). Analisando o período do ano com maior ocorrência de eventos de estiagem dentro de cada fase do fenômeno ENOS, pode-se observar que em anos de $\mathrm{LN}$ o período com maior frequência foi de dezembro a março, que totalizam 173 dos 187 dias de ocorrência, ou seja, 92,51\% dos casos (Tabela 2), em anos de EN foi em janeiro com 27 dias, totalizando $72,97 \%$ durante o fenômeno, e em anos neutros o período de fevereiro até maio $(171-82,21 \%)$. Pela análise do número de municípios atingidos dentro de cada REDEC (Tabela 3), onde contabilizou-se apenas a primeira ocorrência dentro de cada mês em cada município, foi possível verificar a área total de atuação do evento. As REDECs que apresentaram o maior número de municípios atingidos foram a REDEC 2 (273 municípios) e a REDEC 5 (248 municípios) que totalizam $37,89 \%$ de todos os municípios atingidos, e a que apresentou o menor número de municípios atingidos foi a REDEC 8 com nove municípios atingidos $(0,65 \%)$, durante o período de 2003 a 2012 (Tabela 3 e Figura 2). Em relação ao total de municípios distintos que foram atingidos por estiagem, ao longo dos 10 anos de estudo, as REDECs 2 e 5 foram as mais afetadas somando cerca de 153 (33,77\% total) (Tabela 3 e Figura 2), sendo que estas REDECs juntas possuem 153 municípios, ou seja, todos foram atingidos pelo menos uma vez durante os 10 anos estudados por estiagem.

Sendo assim, observou-se que a metade norte do RS (acima de $30^{\circ} \mathrm{S}$ ) foi a que apresentou a maior frequência de ocorrência de estiagem composta pelas REDECs 2, 3, 5, 7, 9 e 11, representando $77,70 \%$ do total do evento de estiagem ocorridos (352) nos municípios distintos (Tabela 3 e Figura 2), os valores encontrados são semelhantes aos resultados(Nedel et al., 2012), onde encontraram que $68 \%$ dos municípios afetados por estiagem estavam na metade norte do RS Observaram que os episódios mais intensos foram os eventos ocorridos nos anos 2004, 2005 e 2009, afetando vários municípios do RS, o que concorda com o que foi estudado até agora. 
Tabela 3. Número de municípios atingidos uma única vez por mês e o total de municípios atingidos ao longo do período de estudo (2003-2012). Em que, Total* - número de municípios distintos, Mun* - número total de municípios que compõem cada REDEC.

\begin{tabular}{llllllllllllllll}
\hline REDEC S & $\mathrm{J}$ & $\mathrm{F}$ & $\mathrm{M}$ & $\mathrm{A}$ & $\mathrm{M}$ & $\mathrm{J}$ & $\mathrm{J}$ & $\mathrm{A}$ & $\mathrm{S}$ & $\mathrm{O}$ & $\mathrm{N}$ & $\mathrm{D}$ & Total & Total* & Mun* \\
\hline REDEC 1 & 17 & 19 & 15 & 14 & 7 & 2 & 0 & 0 & 0 & 0 & 0 & 1 & 75 & 41 & 60 \\
REDEC 2 & 76 & 24 & 75 & 43 & 19 & 2 & 0 & 1 & 0 & 0 & 0 & 33 & 273 & 84 & 84 \\
REDEC 3 & 40 & 31 & 41 & 10 & 23 & 9 & 0 & 0 & 0 & 0 & 0 & 12 & 165 & 50 & 50 \\
REDEC 4 & 23 & 10 & 16 & 7 & 12 & 6 & 2 & 1 & 0 & 0 & 0 & 1 & 78 & 27 & 27 \\
REDEC 5 & 65 & 23 & 65 & 35 & 16 & 7 & 4 & 0 & 0 & 0 & 0 & 31 & 246 & 69 & 69 \\
REDEC 6 & 13 & 5 & 9 & 6 & 7 & 4 & 3 & 1 & 1 & 0 & 0 & 1 & 50 & 13 & 13 \\
REDEC 7 & 45 & 25 & 42 & 20 & 12 & 20 & 0 & 1 & 0 & 0 & 0 & 5 & 170 & 45 & 45 \\
REDEC 8 & 2 & 2 & 2 & 3 & 0 & 0 & 0 & 0 & 0 & 0 & 0 & 0 & 9 & 7 & 23 \\
REDEC 9 & 31 & 11 & 26 & 15 & 12 & 0 & 0 & 0 & 0 & 0 & 0 & 0 & 95 & 43 & 52 \\
REDEC 10 & 10 & 8 & 10 & 3 & 5 & 3 & 1 & 0 & 1 & 1 & 0 & 0 & 42 & 14 & 14 \\
REDEC 11 & 54 & 20 & 45 & 13 & 22 & 5 & 0 & 0 & 0 & 0 & 0 & 14 & 173 & 60 & 60 \\
\hline Total & 374 & 178 & 346 & 169 & 135 & 58 & 10 & 4 & 2 & 1 & 0 & 98 & 1377 & 453 & 497 \\
\hline
\end{tabular}

a)

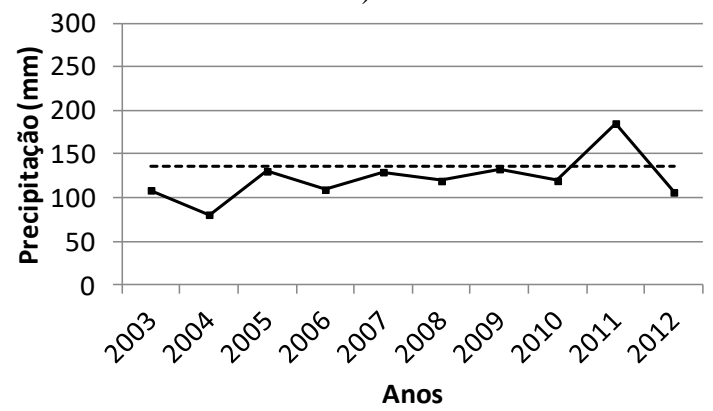

c)

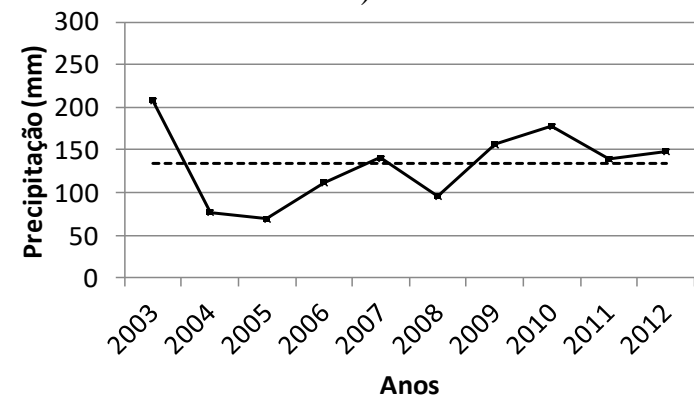

b)

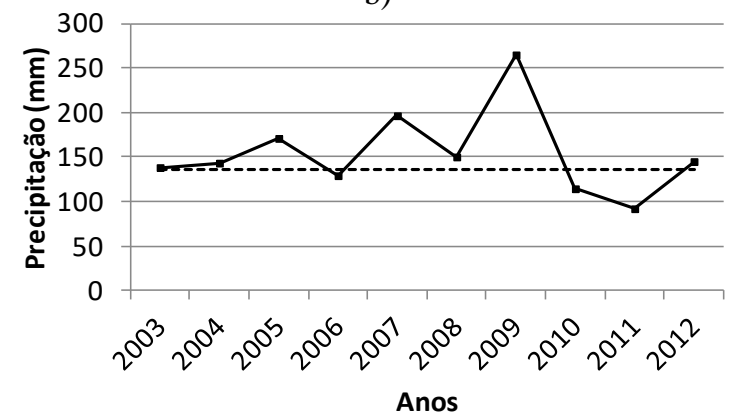

d)

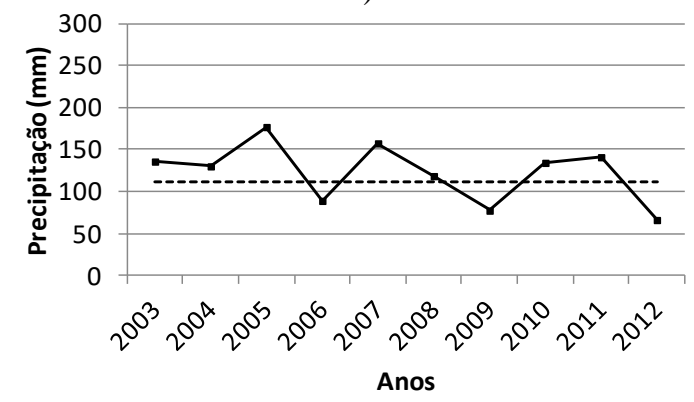

Figura 2. Precipitação média trimestral (mm, linha sólida) e Média trimestral da Normal Climatológica (mm, linha pontilhada) para as estações: (a) Inverno, (b) Primavera, (c) Verão e (d) Outono.

Ao avaliarmos a quantidade de precipitação no RS, durante os anos de estudo, observa-se que o verão e outono (Figura $3 \mathrm{c}$ e $3 \mathrm{~d}$ ), foram as estações onde os valores de precipitação ficaram abaixo da normal climatológica, pois juntos apresentaram o maior número de municípios atingidos pela estiagem, apresentando 1300 registros do ES, representando $94,40 \%$ do total de ocorrências. Por outro lado, as estações da inverno e primavera (Figura 3a e 3b) apresentam desvios positivos de precipitação em relação à normal climatológica.

O impacto da atuação dessas ocorrências de estiagem pode ser ilustrado pelos danos causados à agricultura do RS, principalmente nas safras de 2004/2005 e 2011/2012, que são consideradas as que tiveram as maiores quebras dos últimos 10 anos (FEPAGRO, 2012), coincidindo com os períodos de maior ocorrência de estiagens na área agrícola do Estado. 
Verificou-se que, em ambos os anos (Figura 3 e Figura 4), a variação temporal do NDVI apresentou caracterização da região influenciando diretamente na vegetação, possuindo um ciclo anual bem definido, e o máximo de NDVI ocorre em períodos Neutros, início do período chuvoso na região (inverno e outono), enquanto o mínimo é bem marcante ocorrendo nos mês com atuação da LN, início do período de estiagem. Podemos observar (Figura 3 e 4) ainda que o NDVI variou de -1 a 1 (Torresan et al., 2012), sendo as tonalidades na cor verde referentes a uma maior quantidade de área foliar da vegetação presente e a cor vermelho representa uma região com maior déficit hídrico. $\mathrm{O}$ solo nu ou com vegetação rala apresenta valores positivos, mas não muito elevados. Vegetação densa, úmida e bem desenvolvida apresenta os maiores valores de NDVI, próximos a 1(Sartori et al., 2009). Na Figura 3a nota-se que a vegetação com maior déficit hídrico está na MN do Estado, onde teve regiões que apresentou índices de $-0,76$ a -0,5, em parte devido a altitude dessa região, além disso a atuação do fenômeno EN Modoki em 2004 e EN em janeiro de 2005 que afetou Estado do RS, contribui para que a estiagem fosse mais intensa na $\mathrm{MN}$.
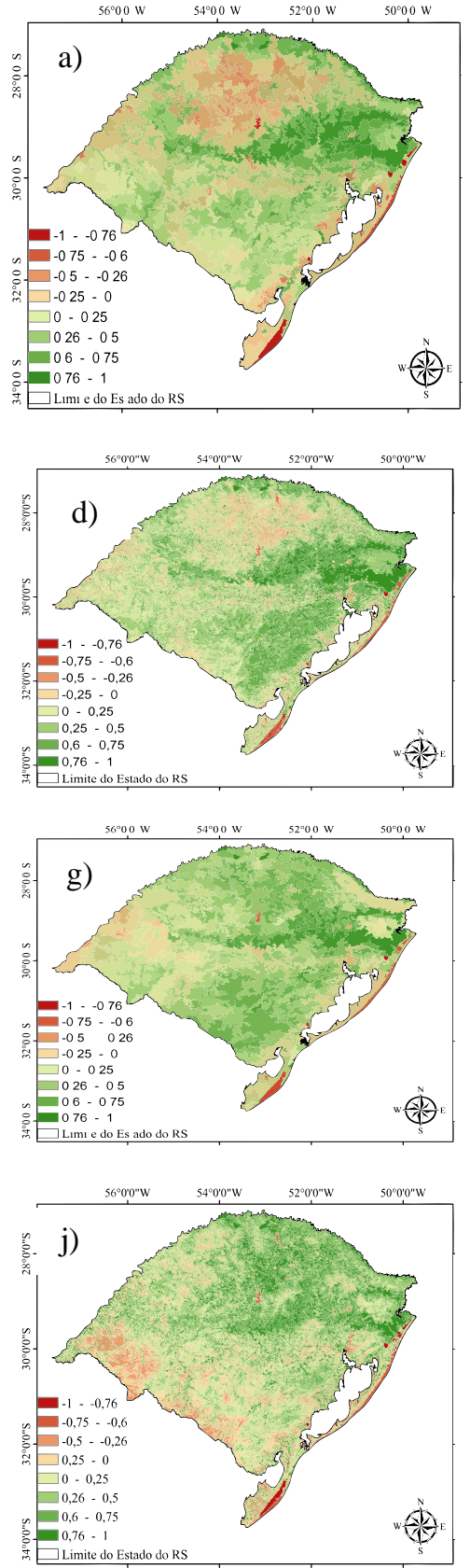
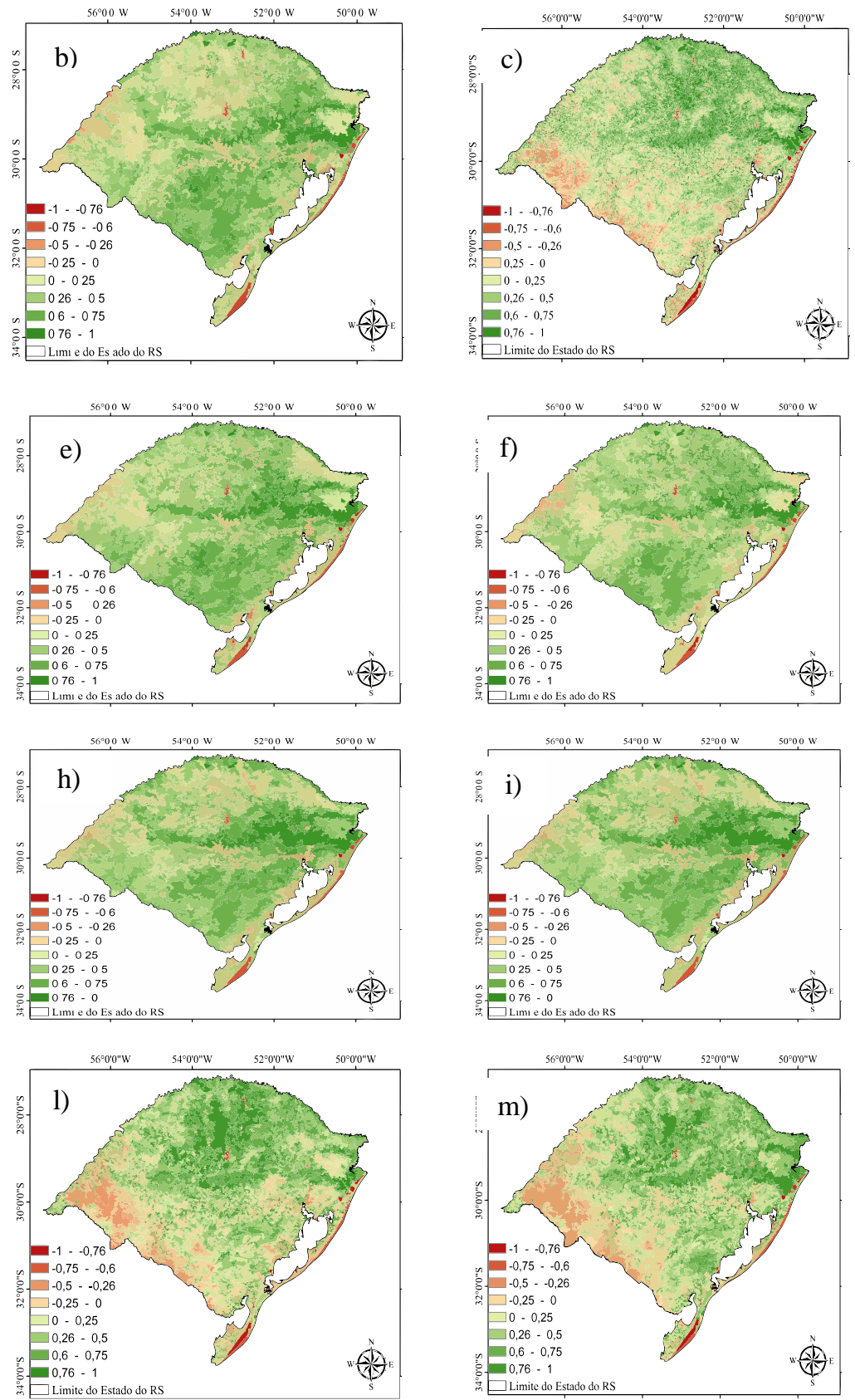

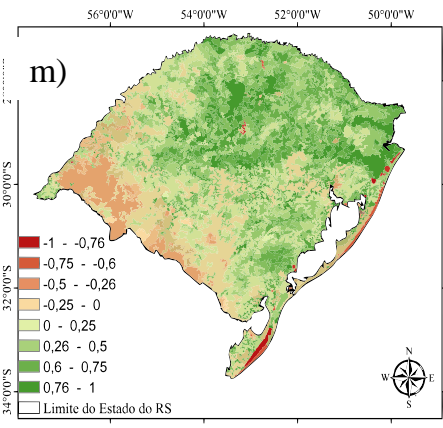

Figura 3. Análise do NDVI para o ano de 2005: a) janeiro, b) fevereiro, c) março, d) abril, e) maio, f) junho, g) julho, h) agosto, i) setembro, j) outubro, l) novembro e m) dezembro. 
Através da análise da Figura 4 verificou se que praticamente todo o Estado do RS foi atingido pela estiagem, principalmente $\mathrm{o}$ começo de 2012, no qual várias regiões apresentaram índices de $-0,76$ a $-0,5$, em que prorrogou por vários meses (Jan-Fev-Mar-Abri). Analisando-se (Figuras 3 e 4), constata-se que grande parte do território estudado apresenta valores negativos, indicando tendência de decréscimo do NDVI ao longo dos dois anos com maior ocorrência de estiagem. Uma parcela significativa apresenta valores próximos de zero (tons claros na figura), relacionados à ausência de tendência e coincidentes com a maior parte das áreas cultivadas.
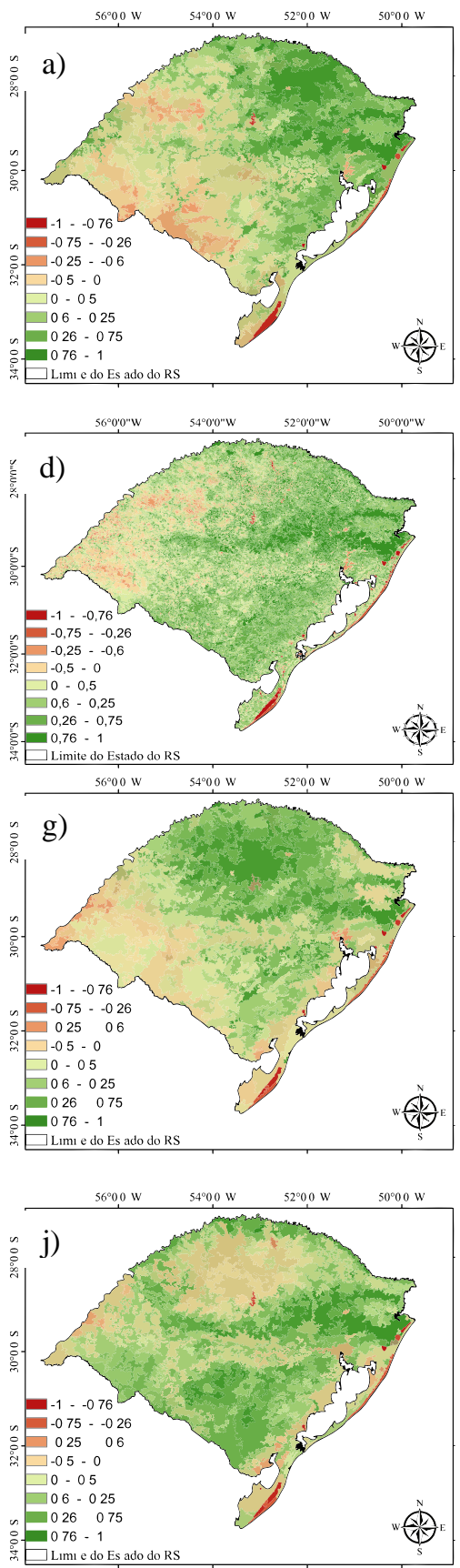
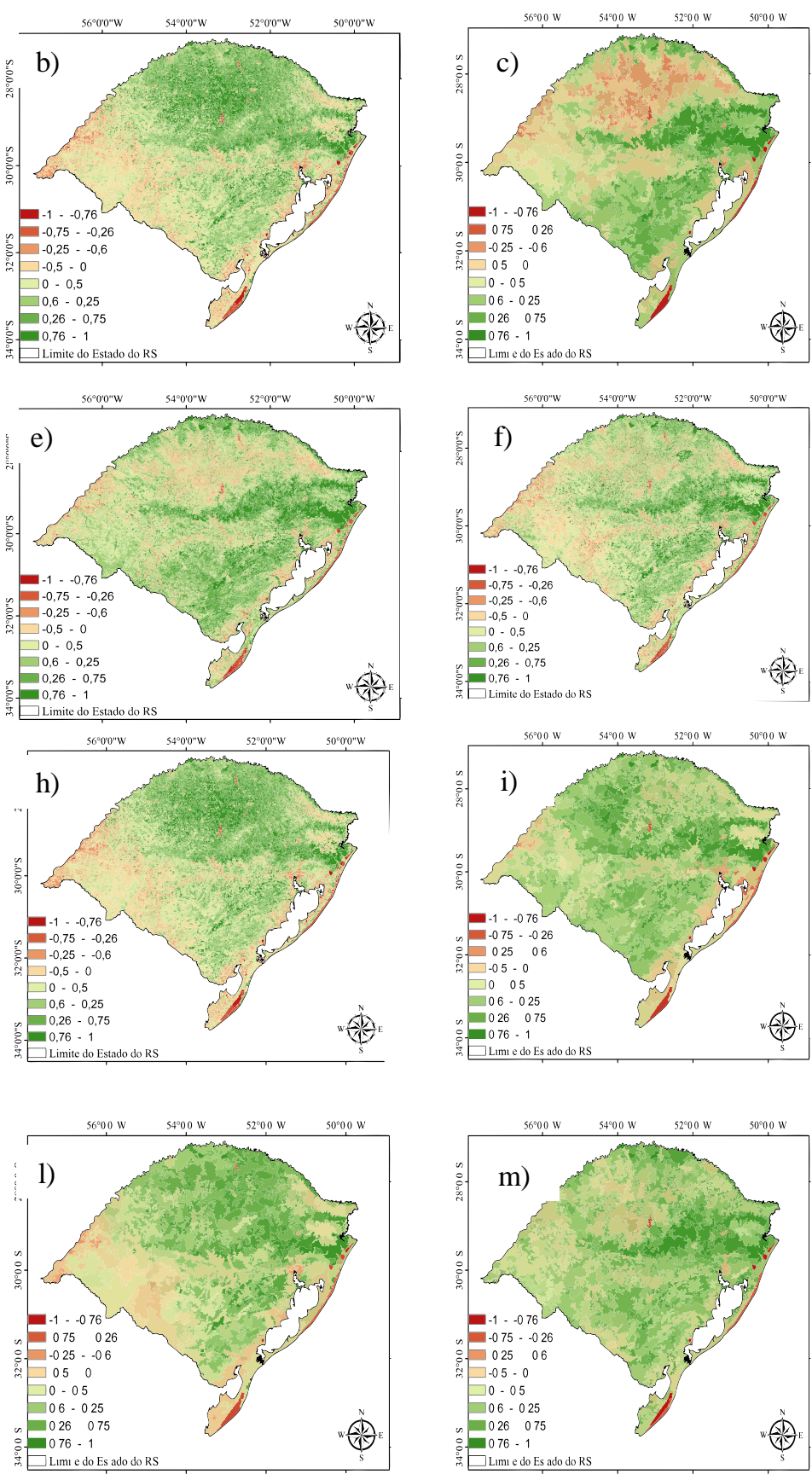

Figura 4. Análise do NDVI para o ano de 2012: a) janeiro, b) fevereiro, c) março, d) abril, e) maio, f) junho, g) julho, h) agosto, i) setembro, j) outubro, l) novembro e m) dezembro. 


\section{CONCLUSÃO}

Com este estudo foi possível verificar que os ESRSr com mais frequentes na área rural foram estiagem, granizo e vendaval, respectivamente (período de 2003 até 2012). Com atuação de ESRSr ao longo de todo o período de estudo, com maior frequência nos períodos de verão e outono.

$\mathrm{O}$ evento de estiagem foi que apresentou maior frequência (2003-2012), principalmente nos anos de 2009 e 2012, já as estações com maior número de ocorrência durante o verão e o outono. A estiagem, em geral ocorre com maior frequência em períodos sem a atuação do fenômeno El Niño Oscilação Sul (ENOS). Mas ao compararmos a ocorrência deste evento dentro das fases do ENOS, é mais frequente em períodos de La Niña e El Niño Modoki.

A metade norte do RS (acima de $30^{\circ} \mathrm{S}$, composta pelas REDECs 2, 3, 5, 7, 9 e 11), foi a que apresentou a maior frequência de ocorrência de estiagem, sendo que nesta, todo municípios que as constituem foram atingidos pelo menos uma vez durante o período de estudo e apresentando maior índices de NDVI.

A grande variabilidade do NDVI em cada ano também se deve aos efeitos climáticos, neste caso, associados a estações mais chuvosas (El Niño) ou mais secas (La Niña).

Os resultados sugerem que o NDVI pode ser usado como um indicador da resposta da vegetação aos efeitos das ações antrópicas ou das mudanças climáticas, especialmente de eventos como El Niño e La Niña. Dessa forma fica evidente a necessidade de estudos mais aprofundados sobre como esse assunto afeta a economia do RS.

\section{AGRADECIMENTOS}

Os autores agradecem a Defesa Civil do Estado do Rio Grande do Sul pela disponibilidade dos dados e informações, e a Coordenação de Aperfeiçoamento de Pessoal de Nível Superior (CAPES) pela bolsa de estudos.

\section{REFERÊNCIAS}

1. AGUIAR, R. Estiagem: como conviver com esse fenômeno? Extensão Rural e Desenvolvimento Sustentável,v.1, n.4, 2005.

2. AMADO, T. J. C.; PONTELLI, C. B.; SANTI, A. L.; VIANA, J. H. M.; SULZBACH, L. A. D. S. Variabilidade espacial e temporal da produtividade de culturas sob sistema plantio direto. Pesquisa Agropecuária Brasileira, v. 42, n. 8, p. 1101-1110, 2007.

3. ARAÚJO, M. DE; JUNIOR, S.; SILVIA, M. Estiagem na região sul do brasil-caracterização por meio de imagens evi/modis. In: CONGRESSO BRASILEIRO SOBRE DESASTRES NATURAIS.2012. Rio Claro. Resumo Expandido... São Paulo: 2012.

4. ASSAD, E. D.; MARIN, F. R.; EVANGELISTA, S. R. Sistema de previsão da safra de soja para o Brasil. Pesquisa Agropecuaria Brasileira, v. 42, n. 5, p. 615-625, 2007.

5. BARTEKO, R.; ANDRADE, A. R. DE; ANTONELI, V. A influência da variabilidade climática e das características geomorfológicas na produção e produtividade agrícola da região centro-sul do Paraná. In: XVI ENCONTRO NACIONAL DOS GEÓGRAFOS.2010. Porto Alegre Resumo Expandido.... Rio Grande do Sul: Associação Brasileira de Geógrafos, 2010, p.111.

6. BERGAMASCHI, HOMERO; DALMAGO, G. A. B.; JOÃO ITO; BIANCHI, CLEUSA ADRIANE MENEGASSI; MÜLleR, A. G. C.; FLÁVIA; HECKLER, B. M. M. Distribuição hídrica no período crítico do milho e produção de grãos. Pesquisa Agropecuaria Brasileira, v. 39, n. 9, p. 831839, 2004.
7. BERLATO, M. A. \& FONTANA, C. El niño e a agricultura da região sul do brasil. Montividel Uruguai. In: Efectos de El Niño sobre la Variabilidad Climática, Agricultura y Recursos Hídricos en el Sudeste de Sudamérica (Impacts and Potential Applications of Climate Predictions in Southeastern South America). 1997.Montevideo Resumo Expandido... Uruguai,1997. p. 27-30.

8. CAVALCANTI, I. F. D. A.; FERREIRA, N. J.; SILVA, M. G. A. J. DA; DIAS, M. A. F. D. S. Tempo e Clima.Oficina de textos, 2009.

9. CAMPOS, C. R. J. D \& EICHHOLZ, C. W. Características físicas dos Sistemas Convectivos de Mesoescala que afetaram o Rio Grande do Sul no período de 2004 a 2008. Revista Brasileira de Geofísica, v. 29, n. 2, p. 331-345, 2011.

10. CAMPOS, C. R. J. D \& SILVA, M.V.D. Impacto de sistemas meteorológicos no regime hídrico do Rio Grande do Sul em 2006. Revista Brasileira de Geofísica, São Paulo, v. 28, n. 1, p. 121-136, 2010 . Available from $<$ http://www.scielo.br/scielo.php?script=sci_arttext\&pid=S010 2-261X2010000100010\&lng=en\&nrm=iso $>. \quad$ access on 29 Oct. 2015

11. CERA, J. C \& FERRAZ, S. E. T. VARIAÇÕES CLIMÁTICAS NA PRECIPITAÇÃO NO SUL DO BRASIL NO CLIMA PRESENTE E FUTURO. Revista Brasileira de Meteorologia, v. 30, n. 1, p. 81-88, 2015.

12. COSTA, A. M. Pobreza E Vulnerabilidade De Agricultores Familiares De Santo Cristo / RS : Uma Análise Da Seca a Partir Da Abordagem Das Capacitações, 2006. 152p. Dissertação( Mestrado Desenvolvimento Rural)UNIVERSIDADE FEDERAL DO RIO GRANDE DO SUL 
FACULDADE DE CIÊNCIAS ECONÔMICAS PROGRAMA DE PÓS-GRADUAÇÃO EM DESENVOLVIMENTO RURAL. 13. CUNHA, G.R. El Niño \& agricultura: a arte de administrar riscos. Plantio Direto, v.3, n.42, p. 17-21, 1997.

14. DA SILVA, P. R. N. A queda da receita e a estiagem geram dificuldades em um contexto de moeda estável. Indicadores Econômicos FEE, v. 24, n. 1, p. 53-70, 1996.
15. DA CUNHA, R.;PIRES,J.L.F.;DALMAGO,G.A.,SANTI,

A.,PASINATO,A.;DA SILVA,A.A.G.;ASSAD,E.D.;DA ROSA,C. El Niño/La Niña-Oscilação Sul e seus impactos na agricultura brasileira: fatos, especulações e aplicações. Revista Plantio Direto, v. 20, n. 121, p. 18-22, 2011.

16. DE MOURA, B. P., SANTOS, T. M. M., DA COSTA, M. L. B., DA SILVA, H. G., JUNIOR, J. B. T., DE AZEVEDO, C. F.14697-Efeitos da estiagem na produção familiar no sítio Guritiba, Queimadas-PB. Cadernos de Agroecologia, v. 8, n. 2, 2013.

17. DE VARGAS JR, V. R \& DE CAMPOS, C. R. J. Eventos Severos no Rio Grande do Sul no Período 2004-2008. Anuário do Instituto de Geociências - UFRJ, v. 38, n.1, p. 137-146, 2015.

18. GOERL, R. F.; KOBIYAMA, M.; CORREA, G. P.; ROCHA, H. L.; GIGLIO, J. N. Desastre Hidrológico Resultante das Chuvas Intensas em Rio dos Cedros - SC. In: XVIII Simpósio Brasileiro de Recursos Hídricos.2009, Campo Grande. Resumos Expandidos.... Mato Grosso do Sul: Associação Brasileira de Recursos Hídricos,2009, p.1-19.

19. GRIMM, A. M.; BARROS, V. R.; DOYLE, M. E. Climate Variability in Southern South America Associated with El Niño and La Niña Events. American Meteorological Society, v. 13, n. 1, p. 35-58, 2000.

20. JACÓBSEN, L. Efeitos associados a El Nino e La Nina na vegetação do estado do Rio Grande do Sul, observados através do NDVI/NOAA. Revista Brasileira de Meteorologia, v. 19, n. 2, p. 129-140, 2004.

21. JUNIOR, J. G. G \& PEZZI, L. P. O EL NIÑO "MODOKI" E SEU IMPACTO SOBRE A SECA DE 2005 NA AMAZÔNIA. In: IV Encontro Sul Brasileiro de Meteorologia,2011, Pelotas,Resumos Expandindos... Rio Grande do Sul: Associação Brasileira de Meteorologia,2011, p. 1-10.

22. LAZZARI, M. R. \& FEE, E. Análise setorial Agropecuária Agropecuária gaúcha em 2005 : estiagem, câmbio e crise desempenho da lavoura de grãos. Indicadores Econômicos da Fee,v.33,n.4, p. 41-50, 2006.

23. LAZZARI, R. M. Safra 2004 / 05 de grãos de verão do RS : produção e preços em baixa. Indicadores Econômicos da Fee, v. 33, n. 2 , p. $47-64,2005$.

24. NEDEL, A. S.; SAUSEN, T. M.; SAITO, S. M. Zoneamento dos desastres naturais ocorridos no estado do Rio Grande do Sul no período 2003 - 2009 - Parte I: Seca. Revista Brasileira de Meteorologia, v. 27, n. 2, p. 119-126, 2012.

25. PELlEGRINO, G. Q.; ASSAD, E. D.; MARIN, F. R. Mudanças Climáticas Globais e a Agricultura no Brasil. Revista Multiciência, n. 8, p. 139-162, 2007.

26. RASERA, G \& CAMPOS, C. R. J. DE. Anuário do Instituto de Geociências - UFRJ Análise Sazonal das Regiões do Rio Grande do Sul Atingidas por Eventos Severos Gerados por SCM no Período de 2004 a 2008. Anuário do Instituto de Geociências, v. 36, n. 2, p. 61-69, 2013.
27. REIS, J.; MADRUGA, R. A.; NARVAES, I. D. S.; LIMA JUNIOR, E. R.; SAUSEN, T. M. Avaliação dos desastres naturais ocorridos no Rio Grande do Sul de 2007 a 2011.In: XV Simpósio Brasileiro de Sensoriamento Remoto SBSR,2011,Curitiba. Resumo Expandidos..., Paraná: Associação Brasileira de Meteorologia, 2011, p.48-28.

28. REIS, J. T., MADRUGA, R. A., NARVAES, I. D. S., JUNIOR, E. R. L., SAUSEN, T. M. Avaliação dos desastres naturais ocorridos no Rio Grande do Sul de 2007 a 2011.In: Congresso Brasileiro Sobre Desastres Naturais, 2012. Rio Claro. Resumo Expandido... São Paulo: 2012, p.1-11.

29. RIBEIRO, M. G.; TANAJURA, E. L. X.; CENTENO, J. A. S. Monitoramento de período de seca utilizando subtração de imagem NDVI: Estudo de caso do Reservatório do Irai - PR.In: Simpósio Brasileiro de Sensoriamento Remoto, 2007. Florianópolis.Resumo Expandido... Santa Catarina : 2007, p. $1055-1062$.

30. SANJARABDOULAEV, A. S; GOMES, O. R. G. Sistemas de mesoescala de precipitações no Rio Grande do Sul. Parte 1: Classificação dos simestmas de mesoescala de precipitações. Revista Brasileira de Meteorologia, v. 13, n. 2, p. 57-74, 1998.

31. SALIO, P.; NICOLINI, M.; ZIPSER, E. J. Mesoscale Convective Systems over Southeastern South America and Their Relationship with the South American Low-Level Jet. Monthly Weather Review, v. 135, n. 4, p. 1290-1309, 2007.

32. DOS SANTOS, R. S., COSTA, L. C., CHOHAKU, G., SEDIYAMA, B. G. L., FLÁVIO, R. A. D. O. E., JUSTINO, B. Avaliação da relação seca/produtividade agrícola em cenário de mudanças climaticas. Revista Brasileira de Meteorologia, v. 26, n. 2, p. 313-321, 2011

33. SARTORI, A. . D. C.; SILVA, R. F. B. DA; PIANUCCI, M. .; ZIMBACK, C. R. . Influência do período de estiagem no Índice de Vegetação (NDVI), no município de Botucatu-SP.In: Simpósio Brasileiro de Sensoriamento Remoto - SBSR,2009. Natal. Resumo Expandido... Rio Grande do Norte, 2009, p. 4363-4369.

34. STRECK, N. A.; BURIOL, G. A.; HELDWEIN, A. B.; GABRIEL, L. F.; PAULA, G. M. DE. Associação da variabilidade da precipitação pluvial em Santa Maria com a Oscilação Decadal do Pacífico. Pesquisa Agropecuaria Brasileira, v. 44, n. 12, p. 1553-1561, 2009.

35. TEDESCHI, R. G.; CAVALCANTI, I. F. A. Influência dos ENOS Canônico e Modoki na precipitação da América do Sul. In: XIII CONGRESSO BRASILEIRO DE METEOROLOGIA,2004.Fortaleza, Resumo Expandido..., Ceará, 2004, p. 1-4.

36. TORRESAN, E.; VICENTE, L. E.; LUISBOLFE, E. Estiagem na região Sul do Brasil monitoramento através de imagens de satélite drought in southerb Brazil monitored through.In: XX Simpósio Brasileiro de Recursos Hídricos.2013, Bento Gonçalves Resumo Expandido... ,Rio Grande do Sul, 2013, p. 1-8.

Manuscrito recebido em: 06 de Maio de 2016 Revisado e Aceito em: 18 de Setembro de 2016 